\title{
Compulsive sexual behavior: A twelve-step therapeutic approach
}

\author{
YANIV EFRATI ${ }^{1 *}$ and MATEUSZ GOLA ${ }^{2,3}$ \\ ${ }^{1}$ Faculty of Education and Society and Culture, Beit-Berl College, Kfar Saba, Israel \\ ${ }^{2}$ Institute of Psychology, Polish Academy of Sciences, Warsaw, Poland \\ ${ }^{3}$ Swartz Center for Computational Neuroscience, Institute for Neural Computations, \\ University of California San Diego, San Diego, CA, USA
}

(Received: August 30, 2017; revised manuscript received: February 13, 2018; accepted: March 24, 2018)

\begin{abstract}
Background and aims: Sexuality is natural to human life and inseparable from it, yet some individuals develop compulsive sexual behavior (CSB). Many individuals with CSB seek treatment in free self-support groups based on the twelve-step program. This program was extensively studied in substance abuse disorders (e.g., Alcoholics Anonymous), but little is known about its efficiency in CSB. Methods: We "assesed" questionnaire data on sociodemographical-, psychological-, and recovery-related factors from 97 male participants of Sexaholics Anonymous (SA) programs in Israel. Results: Our results indicated that advancement in the SA program, measured as a current step of the program, is significantly related to lower levels of sexual-related overall sense of helplessness, avoidant help-seeking, self-control, overall CSB, and sexual suppression. It is also related to the higher well-being. Discussion: This is the first study to examine psychological factors of CSB recovery process in twelve-step groups, and future research is needed to replicate our results within a longitudinal study.
\end{abstract}

Keywords: compulsive sexual behavior, recovery, 12-step groups, Sexaholics Anonymous

\section{INTRODUCTION}

From early childhood on, sexuality plays an important role in our life and our relationships with others. This natural and integral part of our being seems to carry its burden of the problem, and therapists report growing number of men and women seeking the help of clinicians and online forums for various sexuality-related issues, among them compulsive sexual behavior (CSB; Gola, Lewczuk, \& Skorko, 2016; Lewczuk, Szmyd, Skorko, \& Gola, 2017).

Hypersexuality or CSB is a repetitive and intense preoccupation with sex. This preoccupation can take the form of fantasies, urges, and behaviors, all of which may lead to adverse consequences, including impaired social and occupational functionings and deep distress (Kafka, 2010). Estimations from the United States indicate that $3 \%-6 \%$ of the population develops hypersexual behavior (Carnes, Green, \& Carnes, 2010; Coleman, 1992; Reid, 2013; SASH, 2008). Considering this prevalence, it is surprising that it took so long to recognise and classify hypersexuality and its implications in classifications of disorders (Gola \& Potenza, 2016; Kraus, Voon, \& Potenza, 2016; Kraus et al., 2018; Potenza, Gola, Voon, Kor, \& Kraus, 2017; Reid, 2013).

Despite growing popular public awareness to CSB, and a growing body of research (Gola, Wordecha, Sescousse, \& Marchewka, 2016; Gola et al., 2017; Kaplan \& Krueger, 2010; Kor, Fogel, Reid, \& Potenza, 2013;
Kraus, Voon, Kor, \& Potenza, 2016; Kraus, Voon, \& Potenza, 2016; Kühn \& Gallinat, 2016; Love, Laier, Brand, Hatch, \& Hajela, 2015; Reid, 2010; Reid, Garos, $\&$ Carpenter, 2011), CSB remains in a condition awaiting professional recognition (Kraus et al., 2018; Potenza et al., 2017). The fifth edition of Diagnostic and Statistical Manual of Mental Disorders (American Psychiatric Association, 2013) offers a means of diagnosis (Krueger, 2016), and International Classification of Diseases (ICD-10; WHO, 1992) includes the categories Excessive Sexual Drive (F52.7) and Excessive Masturbation (F98.8). However, it neither describes the mechanisms underlying CSB or directions for treatment. At present, World Health Organization (WHO, 2017) proposed to include CSBs in the upcoming ICD-11 classification (Kraus et al., 2018; Potenza et al., 2017), but final decision will be made in 2018. People who seek help for their CSB often base on self-diagnosis and intuitive analogy between their sexual behavior and drug or alcohol use. Common choices among treatment seekers are twelve-step self-support groups, clinics offering pharmacotherapy (Gola \& Potenza, 2016; Krause, Meshberg-Cohen, Martino, Quinones, \& Potenza, 2015), or individual psychological treatment (Gola, Lewczuk, et al., 2016). Here, we focus on individuals participating in one of the twelve-step programs.

* Corresponding author: Yaniv Efrati, PhD; Faculty of Education and Society and Culture, Beit-Berl College, Kfar Saba 4490500, Israel; Phone: +972 545800 094; E-mail: ypefrati@gmail.com

This is an open-access article distributed under the terms of the Creative Commons Attribution-NonCommercial 4.0 International License, which permits unrestricted use, distribution, and reproduction in any medium for non-commercial purposes, provided the original author and source are credited, a link to the CC License is provided, and changes - if any - are indicated. 


\section{THE SEXAHOLICS ANONYMOUS (SA) TWELVE-STEP PROGRAM}

SA has hundreds of support groups worldwide. For example, there are about $60 \mathrm{SA}$ groups in Israel offering support for around 550 men and 50 women with CSB (C. David, Personal communication from SA services, 2017), which makes it the most popular self-help program for CSB in Israel. It is run independently without professionals or government supervision or regulation. In addition, there are a few institutions that offer treatment for CSB to adolescents and adults on an individual basis. There are no official records as to the number of treatment seekers for CSB.

The twelve-step approach was formulated in the 1930s and publicized in The Big Book by Bill Wilson and his collaborators who created a community of individuals willing to recover from alcohol addiction (Wilson, 1939/2001) - known as Alcoholics Anonymous (AA). Since then, the AA program has been the philosophy and practice underlying all "Anonymous" groups, including among them Narcotics Anonymous (NA) or Sexaholics Anonymous (SA). One of the longitudinal studies (Ouimette, Moos, \& Finney, 1998) showed that 1 year after outpatient treatment, $29 \%$ of patients with alcohol-use disorder maintained abstinent; whereas among individuals who combined outpatient treatment with AA 12-step program, it was $62 \%$. In conditions with detoxication only and detoxications combined with 12 -step program, it was $23 \%$ and $49 \%$, respectively. Other longitudinal studies comparing AA twelve-step program with outpatient treatment also showed its effectiveness (Humphreys \& Moos, 1996; Pisani, Fawcett, Clark, \& McGuire, 1993; Walsh et al., 1991).

Unlike people with alcohol addiction, those with CSB have a choice of several twelve-step programs. In the United States, there are programs called Sex Addicts Anonymous (Carnes, Delmonico, \& Griffin, 2001; Schneider \& Weiss, 2001), Sexual Compulsives Anonymous, Sex and Love Addicts Anonymous, Sexual Recovery Anonymous, and Sexaholics Anonymous. Each of these programs is based on the 12 steps and 12 traditions of AA (Schneider \& Weiss, 2001) and uses the dual model of disease and spirituality to deal with addiction (Chapman, 1996; Galanter, Dermatis, Post, \& Sampson, 2013; Kauffman \& Poulin, 1996; McCrady, 1998). According to this model, addiction is viewed as an advanced-stage chronic disease, a stage at which individual is no longer in control of his life (Jellinek, 1960). The disease/addiction is perceived as external to the person, i.e., it is incurable and can lead to insanity, but can be temporarily halted by total abstinence from using the harmful substance (DuPont \& McGovern, 1994; Lemanski, 2000) or - in the case of CSB - abstaining from the harmful behavior. According to the 12-step terminology as a disease, CSB has three manifestations: physical - the addiction, mental - the craving for certain sexual behaviors, and spiritual - selfishness and self-focus (Ronel, 2012).

The spiritual part of the dual model presents the addict as a helpless individual who has lost self-control and is unable to use his will power. It is only by leaning on a Greater Power that he can restrain from his addictive behavior, and thus spirituality understood as trust in the Greater Power is the solution to the disease (Dupont \& McGovern, 1994;
Kurtz, 1979, 1982; Ronel, 1998). In twelve-step programs, CSB - in analogy to drug addiction - is perceived as a spiritual disease of the self, manifested in denial, lack of understanding of spiritual needs, and a feeling that life is meaningless (Diarmuid, 1994; Harrison, 1984; Kurtz \& Ketcham, 1992). To restore or create a sense of meaning in one's life, the person learns how to deal with the feeling of helplessness and take responsibility for their recovery (Wilson, 1939/2001), then undertakes value-related goals that bring about a feeling of satisfaction (Recker \& Wong, 1988).

The twelve-step program for people with CSB differs from AA or NA, where abstinence is understood as an absolute refrain from substance use, whereas in the twelvestep programs targeting CSB, abstinence may be defined in many different ways (which is a reason for so many programs). Some programs allow participants to select the type of sexual activity that is problematic for them (e.g., pornography, pornography with masturbation, and use of paid sexual services); other programs set a single definition for all participants. SA defines sexual abstinence as having only conjugal, heterosexual sex with one's spouse. To date, however, only limited number of studies (e.g., Wright, 2010) examined the correlates between advancement in the SA program and sexual-related cognitions and behaviors.

In this study, we examined relationships between advancement in the recovery process in SA groups and severity of CSB, sexual-related sense of helplessness, treatment-seeking behavior, self-control, social support, sexual suppression, mental health (well-being and distress), and sociodemographic measures.

We predict that advancement in the recovery process in SA groups [specifically indicated by the step number (from 1 to 12)], number of months in the program, number of "clean" months (when one meets SA's definition of sexual sobriety), and attendance frequency will be associated with lower severity of CSB symptoms, sexual-related sense of helplessness, and sexual suppression. We also predict that advancement in the recovery process in SA groups will be related to better mental health (higher well-being and lower distress), better self-control, and more frequent treatment-seeking behavior and perceived social support. We hypothesize that these correlates will hold even after controlling for the person's country of birth (immigrant and native), family history of sexual- or drug-related addiction, years of education, socioeconomic status, and age. In addition, we predict that the advancement in the recovery process in SA groups will not affect the persons' mental health and treatment-seeking behavior directly, but through the mediating factors of sexual-related sense of helplessness and sexual suppression.

\section{METHODS}

\section{Participants}

Participants were recruited among Jewish Israeli members of SA groups. Sample consists of 97 individuals $(98 \%$ male), aged $18-55$ years $(M=30.19, S D=7.30)$. Each of 
the participants provided informed consent and the study was approved by the ethical committee.

Among the participants, $31(32 \%)$ reported that they were single, 64 (66\%) married, and $2(2.1 \%)$ divorced. The number of children varied from none (32\%) to $11(1.0 \%)$, with the mean 2.33 children $(S D=2.2)$. Most of the participants (79.4\%) were native Israelis, $5.2 \%$ born in Europe, $3.1 \%$ in the Commonwealth of Independent States - the former Soviet Union, and $12.4 \%$ from English- and Spanish-speaking countries. Participants' years of education ranged from $5(1 \%)$ to $21(1 \%)$; the mean number of years of schooling was $13.57(S D=2.98)$. Among the participants, $27.8 \%$ are educators or consultants, $4.1 \%$ are self-employed, $8.2 \%$ are hi-tech workers, $4.1 \%$ in business, $27.8 \%$ are students, and $27.3 \%$ answered "other." Financially, $12.8 \%$ reported to be in a very good state, $63.9 \%$ reported that their financial state is good, $18 \%$ - poor, and $4.1 \%$ - very poor.

Participants were asked to define their neighborhood, and $5.3 \%$ reported living in a neighborhood that is well above average, $80.4 \%$ reported that their neighborhood is average, $8.2 \%$ - below average, and $2.1 \%$ defined their neighborhood as very much below average. Finally, when asked about addiction in their nuclear family, $2.1 \%$ reported drug addiction, $8.2 \%$ - alcohol abuse, $1 \%$ - gambling, 3.1\% - addicted to medication, $14.4 \%$ - sex, $8.2 \%$ - food, $10.3 \%$ - "other," and $49.5 \%$ reported that they did not know of any addiction in their family. Some participants $-6.4 \%$ - reported cross addictions in their family.

\section{Measures and procedures}

All individuals were assessed using paper questionnaires containing several measures.

Demographic measures. These include number of months in the program (duration of attendance in SA program), number of "clean" months (duration of abstinence defined as no solitary or dyadic sexual activity outside of formal marriage), attendance frequency, step at the SA program, and demographic measures [years of education, socioeconomic status (SES), and age].

Help-seeking styles. This scale was adapted for this study, based on the help-seeking styles delineated by Komissarouk and Nadler (2014). Participants were asked to imagine a situation where their CSB could interfere in achieving their important goal and ways they have found to prevent it. Each item out of the 28 items was rated on a 7-point scale (ranging from -3 - not at all true of me to 3 - very true of me). Ten items assessed respondents' characteristic tendency to cope with difficulty by seeking autonomy-oriented assistance (e.g., "I think the best way to deal with a sex-related problem is to receive training that enables you to solve it on your own"), nine items assessed their characteristic tendency to seek dependency-oriented help (e.g., "I prefer to rely on somebody else who understands the case better than I do, rather than dealing with the sex-related problem myself'), and nine items assessed their tendency to not seek help under similar conditions (e.g., "Even though it occasionally hurts my chances of success, I try to cope with my patterns of sexual behavior on my own"). Reliability analyses (Cronbach's $\alpha$ ) indicated that all three help-seeking behavior measures had adequate reliability: .71 for the dependency-oriented, .60 for autonomy-oriented, and .83 for avoidance-oriented help-seeking styles. Accordingly, we calculated with three measures of help-seeking styles for each participant.

Individual-based CSB (I-CSB). The I-CSB was constructed to meet the need for a tool that reflects CSB which is manifested in sexual fantasies, compulsive sexual thoughts, and spending a great deal of time watching pornography (Efrati \& Mikulincer, 2018). The measure was originally developed to create a better distinction between individual-based (e.g., sexual fantasies, compulsive sexual thoughts, and masturbation) and partnered (interpersonal sexual conquests and repeated infidelity) facets of CSB. The 24-item, self-report questionnaire has four factors: unwanted consequences, lack of control, negative affect, and affect regulation. Participants are asked to rate on a 7-point Likert scale, the degree to which each statement characterizes their feelings ranging from 1 (not at all) to 7 (very much). Examples of such statements are "I turn to sexual fantasies as a way to cope with my problems" (Item 3) or "I feel that my sexual fantasies hurt those around me" (Item 14). The questionnaire was successfully used in a previous study of a non-clinical population and a clinical population participating in a Sexaholics Anonymous twelve-step program (Efrati \& Mikulincer, 2018). In addition, the I-CSB had high construct, convergent, discriminate, and predictive validities. Its clinical cutoff has also criteria validity. Cronbach's $\alpha \mathrm{s}$ were .86 for unwanted consequences, .87 for lack of control, .79 for negative affect, and .85 for affect regulation. We also computed a total CSB score by averaging the 24 I-CSB items (Cronbach's $\alpha=.94$ ), with higher scores reflecting higher CSB. The I-CSB scale has clinical cutoff of 4.1. In the current sample, $82.6 \%$ were above this clinical cutoff.

Helplessness related to CSB. This scale, developed for this study and based on the I-CSB (Efrati \& Mikulincer, 2018), was designed to examine feelings of helplessness generated by CSB. Twelve items were adapted to examine the feeling of shame associated with CSB using the four factors (unwanted consequences, lack of control, negative affect, and affect regulation). Participants were asked to rate on a 7-point Likert scale from 1 (not at all) to 7 (very much), the degree to which each statement characterized their feelings (e.g., Item 9: Resorting to sexual fantasies when dealing with emotional pain makes me feel helpless; Item 11: Every time I use sexual fantasies, I feel helpless). Cronbach's $\alpha$ s were .81 for unwanted consequences, .61 for lack of control, .66 for negative affect, and .84 for affect regulation. We also computed a total Sensation of helplessness of implicit hypersexual behavior score by averaging the 12 items (Cronbach's $\alpha=.91$ ).

Measures of Social support were assessed using the Multidimensional Scale of Perceived Social Support (MPSS; Zimet, Dahlem, Zimet, \& Farley, 1988). The MPSS, a 12-item self-report scale, has three subscales measuring perceived social support from family (e.g., "My family really tries to help me"), friends (e.g., "I have friends with whom I can share my joys and sorrows"), and significant others (e.g., "There is a special person in life who cares about my feelings"). Participants were asked to rate their answers on a 6-point Likert scale ranging from 1 (strongly disagree) to 6 (very strongly agree). In this study, the as were .76 for 
support from friends, .86 for support from significant others, and .86 for support from family. We also computed a total Social support score by averaging the 12 items (Cronbach's $\alpha=.67)$.

Self-control. The Brief Self-Control Scale (Tangney, Baumeister, \& Boone, 2004) measures dispositional selfregulatory behaviors using 13 items rated on a 5-point scale, ranging from 1 (not at all like me) to 5 (very much like me). Example items are "People would say that I have iron selfdiscipline" and "I often act without thinking through all the alternatives." In this study, the Cronbach's $\alpha$ was .81 .

Mental Health Index (MHI-5; Ware, Snow, Kosinski, \& Gandek, 1993). The MHI-5 is a subscale of the RAND SF-36 Quality of Life Scale (Ware et al., 1993). This nonspecific measure of mental health measures the occurrence and degree of psychological distress (usually of anxiety and depression-related distress states) during the past month (Lavikainen, Fryers, \& Lehtinen, 2006) with two items relating to anxiety by asking how much time was spent feeling "very anxious" and "calm and peaceful." Two of the remaining three depression items were selected for comparison with the Composite International Diagnostic Interview Short-Form (CIDI-SF; Kessler, Andrews, Mroczek, Ustun, \& Wittchen, 1998) core questions, namely the items relating to how much time was spent feeling "so down in the dumps that nothing could cheer you up" (Item 2) and feeling "downhearted and blue" (Item 4); depression relating to feeling "happy" (Item 5) was not compared as it did not match the CIDI-SF core questions for depression as closely as Items 2 and 4. The questionnaire was translated into Hebrew (Ahituv, 2014) and back-translated. In this study, we used only two measures - well-being $(\alpha=0.89)$ and distress $(\alpha=0.77)$.

\section{Ethics}

The study was approved by Beit-Berl College's Institutional Review Board. Each participant signed an informed consent form prior to conducting the study, which ensured anonymity of data and confidentiality.

\section{RESULTS}

\section{Data analysis}

Pearson's correlations between engagement in SA's program measures [number of months in the program, duration of sexual abstinence (months) and step number] are presented in Table 1. All variables except attendance frequency appeared to be moderately correlated. To examine the correlates of engagement in SA's program with other measured variables, we conducted a series of Pearson's correlations. Coefficients are presented in Table 2.

Next, we conducted a series of hierarchical regression analyses to examine whether SA's step number predicts a sexually-related sense of helplessness, help-seeking behavior, self-control, CSB, social support, sexual suppression, and mental health above and beyond the contribution of sociodemographic measures (country of birth, family
Table 1. Correlates between engagement in SA's program measures

\begin{tabular}{lllcc}
\hline & & \multicolumn{1}{c}{1} & \multicolumn{1}{c}{2} & 3 \\
\hline 1 & No. of months in SA & \multicolumn{1}{c}{-} & & \\
2 & No. of "clean" months & $0.59^{* * *}$ & - & \\
3 & Attendance frequency & 0.18 & $0.43^{* * *}$ & - \\
4 & Step number & $0.30^{* *}$ & $0.56^{* * *}$ & $0.58^{* * *}$ \\
\hline
\end{tabular}

Note. SA: Sexaholics Anonymous.

$* * p<.01 . * * * p<.001$.

history of sexual-related or drug-related addiction, years of education, SES, and age) and overall duration in the program [number of months in the program and duration of sexual abstinence (months)]. For the first step of the analyses, we introduced following predictors: country of birth ( $1=$ native, $0=$ immigrant), family history of sexual- or drug-related addiction $(1=$ yes, $0=$ no), years of education, SES, and age. For the second step, we added the measures of overall duration in the SA program [number of months in the program and duration of sexual abstinence (months)] as predictors. Finally, in the third step, we added the step at the SA program as predictor. The outcome measures were sexually related overall sense of helplessness, avoidant help-seeking, self-control, overall CSB, social support from family and significant others, sexual suppression, and wellbeing (in keeping with the bidirectional correlations results). Standardized regression coefficients are presented in Table 3.

Finally, to examine the hypothesis that sexually related overall sense of helplessness and sexual suppression will mediate the link between SA's step number and avoidant help-seeking and mental health, we conducted a series of multipath mediation analyses by employing Hayes' (2013) procedure. Significance of mediation paths was estimated by using bias-corrected bootstrap analyses with 5,000 resamplings. The results are summarized in Figure 1.

\section{Missing data handling}

Overall, 4.6\% of the data were missing. Little's (1988) Missing Completely At Random Test indicated that missing data were completely random, $\chi^{2}(454)=417.03, p=.89$. To handle the missing data, we employed Rubin's (2009) Multiple Imputation Technique, which imputes data in 10 data sets using various statistical algorithms. Then, analyses are performed on each of these data sets and an average result is pooled and reported. This technique proved superior to traditional techniques, such as least-wise deletion.

\section{Main results}

The analyses regarding the correlates between the engagement in SA's program measures have indicated that measures were weakly to moderately related with the strongest link between the number of months in the SA program and the number of "clean" months. Even this latter association, however, accounted for a shared variance of only $36 \%$, and so the measures tap unique qualities of the engagement in SA's program. 
A twelve-step therapeutic approach

Table 2. SA's program correlates $(N=89)$

\begin{tabular}{|c|c|c|c|c|}
\hline & No. of months in SA & No. of "clean" months & Attendance frequency & Step number \\
\hline Helplessness of unwanted consequences & -0.04 & -0.20 & -0.01 & $-0.29 * *$ \\
\hline Helplessness of negative affect & -0.03 & -0.14 & 0.03 & $-0.30 * *$ \\
\hline Helplessness of behavioral control & -0.03 & -0.20 & 0.08 & $-0.34 * *$ \\
\hline Helplessness of affect regulation & 0.02 & -0.10 & 0.07 & $-0.28 * *$ \\
\hline Helplessness & -0.02 & -0.18 & 0.05 & $-0.35^{* *}$ \\
\hline Autonomy-oriented help-seeking & -0.06 & -0.07 & 0.05 & 0.12 \\
\hline Avoidant help-seeking & $-0.22 *$ & $-0.37 * * *$ & -0.12 & $-0.27 *$ \\
\hline Dependent help-seeking & -0.16 & 0.02 & -0.03 & 0.01 \\
\hline Self-control & 0.11 & $0.31 * *$ & 0.09 & $0.39 * * *$ \\
\hline Sexual-related unwanted consequences & $-0.27^{*}$ & $-0.34 * *$ & -0.09 & $-0.39 * * *$ \\
\hline Sexual-related negative affect & -0.04 & -0.01 & $-0.27^{*}$ & 0.04 \\
\hline Sexual-related lack of control & $-0.25^{*}$ & $-0.49 * * *$ & -0.02 & $-0.51 * * *$ \\
\hline Sexual-related affect dysregulation & $-0.23 *$ & $-0.38 * * *$ & -0.11 & $-0.28 * *$ \\
\hline CSB & $-0.26^{*}$ & $-0.41 * * *$ & -0.13 & $-0.40 * * *$ \\
\hline Social support from family & -0.06 & $-0.29 * *$ & 0.06 & $-0.22 *$ \\
\hline Social support from friends & -0.20 & $-0.26^{*}$ & $-0.23^{*}$ & -0.19 \\
\hline Social support from significant others & $-0.27 *$ & $-0.38 * * *$ & $-0.25^{*}$ & $-0.25^{*}$ \\
\hline Sexual suppression & $-0.29 * *$ & $-0.31^{*}$ & $-0.24 *$ & $-0.25^{*}$ \\
\hline Well-being & 0.09 & 0.17 & -0.04 & $0.29 * *$ \\
\hline Distress & -0.10 & -0.15 & $-0.22 *$ & -0.14 \\
\hline Years of education & 0.01 & -0.01 & -0.08 & -0.14 \\
\hline SES & 0.01 & -0.07 & 0.09 & 0.06 \\
\hline Age & $0.34 * *$ & $0.22 *$ & -0.03 & $0.23^{*}$ \\
\hline
\end{tabular}

Note. SA: Sexaholics Anonymous; CSB: compulsive sexual behavior; SES: socioeconomic status.

${ }^{*} p<.05 . * * p<.01 . * * * p<.001$.

Table 3. Standardized regression coefficients for predicting SA's correlates by step number, sociodemographic measures, and overall duration in the program

\begin{tabular}{|c|c|c|c|c|c|c|c|c|}
\hline & Helplessness & $\begin{array}{c}\text { Avoidant } \\
\text { help-seeking }\end{array}$ & $\begin{array}{l}\text { Self- } \\
\text { control }\end{array}$ & CSB & $\begin{array}{l}\text { Support } \\
\text { from family }\end{array}$ & $\begin{array}{l}\text { Support } \\
\text { from others }\end{array}$ & $\begin{array}{c}\text { Sexual } \\
\text { suppression }\end{array}$ & $\begin{array}{l}\text { Well- } \\
\text { being }\end{array}$ \\
\hline \multicolumn{9}{|l|}{ Step 1} \\
\hline Country of birth & -0.13 & 0.23 & 0.24 & $-0.29^{*}$ & 0.17 & 0.14 & 0.05 & 0.17 \\
\hline Family history & -0.07 & -0.02 & 0.06 & -0.11 & -0.16 & -0.12 & -0.23 & -0.06 \\
\hline Years of education & -0.24 & -0.05 & 0.08 & -0.16 & -0.10 & 0.18 & -0.21 & -0.11 \\
\hline SES & 0.12 & -0.21 & -0.18 & 0.22 & -0.04 & -0.03 & -0.09 & -0.03 \\
\hline Age & -0.15 & 0.16 & 0.05 & -0.20 & -0.17 & -0.09 & -0.11 & 0.05 \\
\hline$\Delta R^{2}(\%)$ & 10.7 & 10.4 & 8.2 & 15.4 & 9.5 & 7.2 & 10.1 & 4.0 \\
\hline \multicolumn{9}{|l|}{ Step 2} \\
\hline Country of birth & -0.15 & $0.29^{*}$ & 0.22 & -0.25 & 0.17 & 0.19 & 0.11 & 0.17 \\
\hline Family history & -0.08 & -0.01 & 0.06 & -0.10 & -0.17 & -0.11 & -0.22 & -0.06 \\
\hline Years of education & -0.23 & -0.11 & 0.11 & -0.19 & -0.11 & 0.13 & -0.25 & -0.11 \\
\hline SES & 0.09 & -0.20 & -0.16 & 0.23 & -0.07 & -0.02 & -0.07 & -0.02 \\
\hline Age & -0.22 & $0.30^{*}$ & 0.01 & -0.10 & -0.18 & 0.04 & 0.05 & 0.07 \\
\hline No. of months in SA & 0.26 & -0.08 & -0.16 & -0.06 & 0.20 & -0.09 & -0.21 & -0.11 \\
\hline No. of "clean" months & -0.16 & -0.45 & $0.42^{*}$ & -0.31 & -0.25 & $-0.38^{*}$ & -0.29 & 0.11 \\
\hline$\Delta R^{2}(\%)$ & 4.1 & 23.6 & 12.2 & 11.5 & 4.3 & 17.7 & 17.4 & 0.9 \\
\hline \multicolumn{9}{|l|}{ Step 3} \\
\hline Country of birth & -0.17 & $0.28 *$ & 0.24 & -0.27 & 0.17 & 0.18 & 0.10 & 0.19 \\
\hline Family history & -0.03 & 0.02 & 0.02 & -0.05 & -0.16 & -0.11 & -0.19 & -0.09 \\
\hline Years of education & $-0.34 *$ & -0.17 & 0.20 & $-0.31^{*}$ & -0.13 & 0.13 & $-0.31 *$ & -0.02 \\
\hline SES & 0.16 & -0.16 & -0.22 & $0.31^{*}$ & -0.05 & -0.01 & -0.03 & -0.07 \\
\hline Age & -0.11 & $0.36^{*}$ & -0.08 & 0.02 & -0.17 & 0.05 & 0.10 & -0.01 \\
\hline No. of months in SA & 0.20 & -0.12 & -0.11 & -0.13 & 0.19 & -0.09 & -0.24 & -0.06 \\
\hline No. of "clean" months & 0.06 & $-0.32 *$ & 0.24 & -0.07 & -0.22 & $-0.37 *$ & -0.17 & -0.07 \\
\hline Step number & $-0.51 * * *$ & $-0.29^{*}$ & $0.42 * *$ & $-0.55^{* * *}$ & -0.08 & -0.03 & $-0.27 *$ & $0.39 *$ \\
\hline$\Delta R^{2}(\%)$ & 19.0 & 6.3 & 12.9 & 22.5 & 0.5 & 0.1 & 5.6 & 11.6 \\
\hline
\end{tabular}

Note. SA: Sexaholics Anonymous; CSB: compulsive sexual behavior; SES: socioeconomic status.

${ }^{*} p<.05$. ${ }^{* *} p<.01 .{ }^{* * *} p<.001$. 


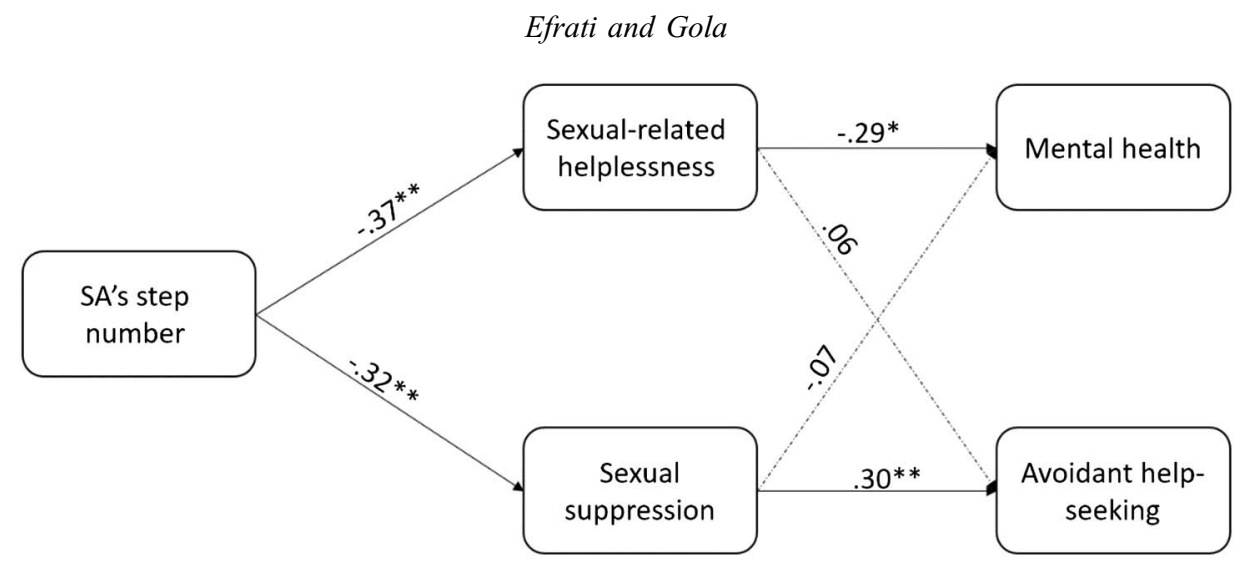

Figure 1. The mediation role of helplessness and sexual suppression in the link between step number, mental health, and avoidant help-seeking. Values relate to standardized coefficients

Regarding the analyses between engagement in SA's program measures and the other main study measures, we found that greater duration in the program and/or duration of abstinence are related with lower intensity of avoidant help-seeking, sexually related unwanted consequences, lack of control, affect dysregulation, severity of CSB, lower sexual suppression, older age, and lower perceived social support from significant others. The number of "clean" months was also linked with higher self-control and lower perceived social support from family and friends (Table 2).

The higher attendance frequency was related to the lower sexually related negative affect, sexual suppression, distress, and perceived social support from friends and significant others. Higher SA step numbers were related to lower sexually related sense of helplessness (unwanted consequences, negative affect, behavioral control, affect regulation, and overall helplessness), the less-avoidant help-seeking, and the higher self-control and well-being. Lower sexually related unwanted consequences, lack of control, affect dysregulation, severity of CSB, and sexual suppression were related to older age, and to lower perceived social support from family and significant others.

In the next step (Table 3), we examined if higher SA step number predicts its correlates above and beyond the contribution of sociodemographic measures and overall duration in the program. The regression analyses indicated that, as expected, advancement in the SA program measured as a current step (of 12) has significantly predicted sexually related overall sense of helplessness, avoidant help-seeking, self-control, overall CSB, sexual suppression, and wellbeing above and beyond the contribution of sociodemographic measures and overall duration in the program. Higher steps were related to lower overall sense of helplessness, avoidant help-seeking, self-control, overall CSB, and sexual suppression and higher well-being. The step number did not significantly predict social support from family and significant others after controlling for sociodemographic measures and overall duration in the program.

In the next step, we examined if overall sense of helplessness and sexual suppression mediate the link between step number, avoidant help-seeking, and mental health. The mediation analyses revealed two mediation paths (Figure 1). The higher the step, the lower the sexual-related sense of helplessness; lower sense of helplessness, in turn, was linked with better mental health $(95 \%$ bias-corrected confidence interval $[0.01,0.25])$. In addition, the higher the step at SA program, the lower the sexual suppression; low sexual suppression, in turn, was linked with less-avoidant helpseeking.

\section{DISCUSSION}

While research has attested to the benefits of the twelve-step AA program (Greenfield \& Tonigan, 2013; Johnson, Finney, \& Moos, 2006; Kelly, Stout, Magill, Tonigan, \& Pagano, 2011; Owen et al., 2003; Wilson, 1939/2001), our review yielded only one qualitative study (Wright, 2010) on the twelve-step programs for individuals with CSB. This study was designed to use quantitavive methods to examine the relationship between advancement in the recovery process in SA groups and severity of CSB, sense of helplessness, treatment-seeking behavior, self-control, social support, sexual suppression, mental health (well-being and distress), and sociodemographic measures. This study points to a possible beneficial correlation between twelve-step programs and CSB.

Two significant components were self-reported in the twelve-step program - duration of attendance and SA step number. It seems that duration of attendance neither reflect the intensity of the work done nor the person's advancement.

Our findings also indicated that the higher the frequency of attendance, the lower the sexually related negative affect, sexual suppression, distress, and perceived social support from friends and significant others. We also found that when an item is high on the SA scale, it is associated with a lower sexually related sense of helplessness (unwanted consequences, negative affect, behavioral control, affect regulation, and overall helplessness). Higher-ranking items are also associated with the lesser the avoidant help-seeking, the higher the self-control and well-being, the lower the sexual-related unwanted consequences, lack of control, affect dysregulation, CSB and sexual suppression, the older the age, and the lower the perceived social support from family and significant others.

More specifically, duration met the needs of the initial aspects of the fantasies and their negative implications on 
participant's mental space, whereas reports of being in a more advanced step met broader needs beyond these fantasies, enabling better day-to-day functioning, less CSB, and especially lesser feelings of helplessness. The lower level of helpless feeling opens the way to seeking help and being supported by others, most importantly.

Following Khantzian's (2014) view of recovery measures, our theoretical model revealed that the higher the step, the lower the sexually related sense of helplessness; lower sense of helplessness, in turn, was linked with better mental health. This finding explains a basic, significant component of the process of recovery in twelve-step programs, as dealing with one's feelings of helplessness allows a person with CSB to take responsibility for recovery and begin the twelve-step journey (Wilson, 1939/2001). In addition, improved mental health indicates recovery and enables members to return to normal functioning in their everyday life (Galanter, 2007).

In addition, our model also indicated that the higher the step, the lower the sexual suppression; low sexual suppression, in turn, was linked with less-avoidant help-seeking. This finding is in line with those of researchers who point to repression of thoughts (Magee, Harden, \& Teachman, 2012; Wegner, Schneider, Carter, \& White, 1987), and specifically to repression of sexual thoughts, as an additional significant component in the development of the mental health and recovery of people with CSB. Narrowing the repression away from the sexual thoughts enables people to seek help and feel enough self-worth to turn to others and be supported by them (Khantzian, 2014; Komissarouk \& Nadler, 2014).

In conclusion, our findings indicate many measures of recovery among members of the SA twelve-step program. We also see the importance of the longer duration of attendance in the program and/or duration of abstinence, as well as the importance of the SA step number on recovery measures in the program. Specifically, as seen in the theoretical mode, the step is a major component of the recovery process. It is in this sense that the veterans of the program make the distinction between abstinence and sobriety (Khantzian, 2014).

\section{Limitations and future directions}

Although our main premises were supported, the study has several limitations. The study is correlational, which precludes the ability for causal conclusions. In other words, it is unclear whether the recovery measures are an outcome of the duration of abstinence or the program step number. Another possibility is that they are related to the fact that a giver participant, a priori, has sufficient resources to handle his or her CSB and, due these resources, is able to progress in the SA program. Longitudinal studies are necessary to determine bidirectional associations over time between participants in the program and their personal resources in the recovery process. In addition, the research population was very homogeneous and local - Jewish Israeli in SA program groups. Future studies should examine other twelve-step groups and diverse ethnic and cultural populations to ascertain the replicability and generalizability of the findings.

\section{Summary}

Despite the limitations of this study, we view this research as an important first step in understanding CSB recovery in a twelve-step program. Participation in a twelve-step program, coupled with individual therapy, has the potential to deliver more focused help to people with CSB. This is especially true when individual therapy does not progress or becomes stuck. It is important to increase therapists' awareness of this program and its benefits, so that when dealing with CSB symptoms, clinicians may consider adding a twelve-step program to the individual therapy for people with CSB.

Funding sources: MG is supported by the scholarship of Ministry of Science and Higher Education of Republic of Poland (469/STYP/10/2015), scholarship of the Kosciuszko Foundation and Polish National Science Centre, OPUS grant (2014/15/B/HS6/03792).

Authors' contribution: YE conducted the study, analyzed the results, and wrote the first draft of the study. MG edited the paper and suggested critical theoretical and empirical additions to the paper.

Conflict of interest: The authors declare no conflict of interest.

\section{REFERENCES}

Ahituv, R. (2014). Dynamics of family discourse about the Shoah and its contribution to forgiveness, agression, and mental health among second- and third-generation individuals in Europe and Israel. Unpublished PhD Dissertation, Bar-Ilan University, Ramat-Gan, Israel (Hebrew).

American Psychiatric Association. (2013). Diagnostic and statistical manual of mental disorders (DSM-5). Arlington, VA: American Psychiatric Association.

Carnes, P., Delmonico, D. L., \& Griffin, E. (2001). In the shadows of the net. Center City, MN: Hazelden.

Carnes, P., Green, B., \& Carnes, S. (2010). The same yet different: Refocusing the Sexual Addiction Screening Test (SAST) to reflect orientation and gender. Sexual Addiction \& Compulsivity, 17(1), 7-30. doi:10.1080/10720161003604087

Chapman, R. J. (1996). Spirituality in the treatment of alcoholism: A worldview approach. Counseling and Values, 41(1), 39-50. doi:10.1002/j.2161-007X.1996.tb00861.x

Coleman, E. (1992). Is your patient suffering from compulsive sexual behavior? Psychiatric Annals, 22(6), 320-325. doi:10.3928/0048-5713-19920601-09

Diarmuid, O. M. (1994). Spirituality, recovery, and transcendental meditation. Alcoholism Treatment Quarterly, 11(1-2), 169-184. doi:10.1300/J020v11n01_05

DuPont, R. L., \& McGovern, J. P. (1994). A bridge to recovery: An introduction to 12 steps programs. Washington, DC: American Psychiatric Press.

Efrati, Y., \& Mikulincer, M. (2018). Individual-based Compulsive Sexual Behavior Scale: Its development and importance in 
examining compulsive sexual behavior. Journal of Sex \& Marital Therapy, 44(3), 249-259. doi:10.1080/0092623X. 2017.1405297

Galanter, M. (2007). Spirituality and recovery in 12-step programs: An empirical model. Journal of Substance Abuse Treatment, 33(3), 265-272. doi:10.1016/j.jsat.2007.04.016

Galanter, M., Dermatis, H., Post, S., \& Sampson, C. (2013). Spirituality-based recovery from drug addiction in the Twelve-Step Fellowship of Narcotics Anonymous. Journal of Addiction Medicine, 7(3), 189-195. doi:10.1097/ADM.0b013 e31828a0265

Gola, M., Lewczuk, K., \& Skorko, M. (2016). What matters: Quantity or quality of pornography use? Psychological and behavioral factors of seeking treatment for problematic pornography use. The Journal of Sexual Medicine, 13(5), 815-824. doi:10.1016/j.jsxm.2016.02.169

Gola, M., \& Potenza, M. N. (2016). Paroxetine treatment of problematic pornography use: A case series. Journal of Behavioral Addictions, 5(3), 529-532. doi:10.1556/2006.5.2016.046

Gola, M., Wordecha, M., Sescousse, G., \& Marchewka, A. (2016). Visual sexual stimuli - Cue or reward? A perspective for interpretation of brain imaging findings on human sexual behaviors. Frontiers in Human Neuroscience, 10, 402. doi:10. 3389/fnhum.2016.00402

Gola, M., Wordecha, M., Sescousse, G., Lew-Starowicz, M., Kossowski, B., Wypych, M., Potenza, M., \& Marchewka, A. (2017). Can pornography be addictive? An fMRI study of men seeking treatment for problematic pornography use. Neuropsychopharmacology, 42(10), 2021-2031. doi:10.1038/ npp. 2017.78

Greenfield, B. L., \& Tonigan, J. S. (2013). The general Alcoholics Anonymous tools of recovery: The adoption of 12-step practices and beliefs. Psychology of Addictive Behaviors, 27(3), 553-561. doi:10.1037/a0029268

Harrison, J. (1984). Love your disease. London/Melbourne: Angus and Robertson.

Hayes, A. F. (2013). Introduction to mediation, moderation, and conditional process analysis: A regression-based approach. New York, NY: Guilford Press.

Humphreys, K., \& Moos, R. H. (1996). Reduced substance abuserelated health care costs among voluntary participants in Alcoholics Anonymous. Psychiatric Services, 47(7), 709713. doi:10.1176/ps.47.7.709

Jellinek, E. M. (1960). The disease concept of alcoholism. New Haven, CT: Hill House Press.

Johnson, J. E., Finney, J. W., \& Moos, R. H. (2006). End-of-treatment outcomes in cognitive-behavioral treatment and 12-step substance use treatment programs: Do they differ and do they predict 1-year outcomes? Journal of Substance Abuse Treatment, 31(1), 41-50. doi:10.1016/j.jsat.2006.03.008

Kafka, M. P. (2010). Hypersexual disorder: A proposed diagnosis for DSM-V. Archives of Sexual Behavior, 39(2), 377-400. doi:10.1007/s10508-009-9574-7

Kaplan, M. S., \& Krueger, R. B. (2010). Diagnosis, assessment, and treatment of hypersexuality: Annual review of sex research. Journal of Sex Research, 47(2-3), 181-198. doi:10. 1080/00224491003592863

Kauffman, S. M., \& Poulin, J. (1996). Coherency among substance abuse models. Journal of Sociology and Social Welfare, 13, 163-174. Retrieved from http://scholarworks.wmich.edu/jssw/ vol23/iss $3 / 1$
Kelly, J. F., Stout, R. L., Magill, M., Tonigan, J., \& Pagano, M. E. (2011). Spirituality in recovery: A lagged mediational analysis of Alcoholics Anonymous' principal theoretical mechanism of behavior change. Alcoholism, Clinical and Experimental Research, 35(3), 454-463. doi:10.1111/j.15300277.2010.01362.x

Kessler, R. C., Andrews, G., Mroczek, D., Ustun, B., \& Wittchen, H-.U. (1998). The World Health Organization Composite International Diagnostic Interview Short-Form (CIDI-SF). International Journal of Methods in Psychiatric Research, 7(4), 171-185. doi:10.1002/mpr.47

Khantzian, E. J. (2014). A psychodynamic perspective on the efficacy of 12-step programs. Alcoholism Treatment Quarterly, 32(2-3), 225-236. doi:10.1080/07347324.2014.907027

Komissarouk, S., \& Nadler, A. (2014). "I" seek autonomy, "We" rely on each other: Self-construal and regulatory focus as determinants of autonomy- and dependency-oriented helpseeking behavior. Personality and Social Psychology Bulletin, 40(6), 726-738. doi:10.1177/0146167214524444

Kor, A., Fogel, Y. A., Reid, R. C., \& Potenza, M. N. (2013). Should hypersexual disorder be classified as an addiction? Sexual Addiction \& Compulsivity, 20(1-2), 27-47. doi:10. 1080/10720162.2013.768132

Kraus, S., Krueger, R., Briken, P., First, M., Stein, D., Kaplan, M., Voon, V., Abdo, C. H. N., Grant, J. E., Atalla, E., \& Reed, G. (2018). Compulsive sexual behaviour disorder in the ICD-11. World Psychiatry, 17(1), 109-110. doi:10.1002/wps.20499

Kraus, S. W., Meshberg-Cohen, S., Martino, S., Quinones, L. J., \& Potenza, M. N. (2015). Treatment of compulsive pornography use with naltrexone: A case report. The American Journal of Psychiatry, 172(12), 1260-1261. doi:10.1176/appi.ajp.2015. 15060843

Kraus, S. W., Voon, V., Kor, A., \& Potenza, M. N. (2016). Searching for clarity in muddy water: Future considerations for classifying compulsive sexual behavior as an addiction. Addiction, 111(12), 2113-2114. doi:10.1111/add.13499

Kraus, S. W., Voon, V., \& Potenza, M. N. (2016). Should compulsive sexual behavior be considered an addiction? Addiction, 111(12), 2097-2106. doi:10.1111/add.13297

Krueger, R. (2016). Diagnosis of hypersexual or compulsive sexual behavior can be made using ICD-10 and DSM-5 despite rejection of this diagnosis by the American Psychiatric Association. Addiction, 111(12), 2110-2111. doi:10.1111/add.13366

Kühn, S., \& Gallinat, J. (2016). Neurobiological basis of hypersexuality. International Review of Neurobiology, 129, 67-83. doi:10.1016/bs.irn.2016.04.002

Kurtz, E. (1979). Not God: A history of Alcoholics Anonymous. Center City, MN: Hazelden Educational Materials.

Kurtz, E. (1982). Why AA works? Journal of Studies on Alcohol, 43(1), 38-80. doi:10.15288/jsa.1982.43.38

Kurtz, E., \& Ketcham, K. (1992). The spirituality of imperfection. New York, NY: Bantam.

Lavikainen, J., Fryers, T., \& Lehtinen, V. (Eds.). (2006). Improving mental health information in Europe. Proposal of the MINDFUL Project. Helsinki, Finland: STAKES.

Lemanski, M. J. (2000). Addiction alternatives for recovery. Humanist, 60, 14-18. Retrieved from https://search.proquest. com/openview/70c2a7a024bdeb3c9d9921416ac1cab2/1?pqorigsite $=$ gscholar \&cbl $=35529$

Lewczuk, K., Szmyd, J., Skorko, M., \& Gola, M. (2017). Treatment seeking for problematic pornography use among women. 
Journal of Behavioral Addictions, 6(4), 445-456. doi:10.1556/ 2006.6.2017.063

Little, R. J. (1988). A test of missing completely at random for multivariate data with missing values. Journal of the American Statistical Association, 83(404), 1198-1202. doi:10.1080/ 01621459.1988 .10478722

Love, T., Laier, C., Brand, M., Hatch, L., \& Hajela, R. (2015). Neuroscience of Internet pornography addiction: A review and update. Behavioral Sciences, 5(3), 388-433. doi:10.3390/ bs5030388

Magee, J. C., Harden, K. P., \& Teachman, B. A. (2012). Psychopathology and thought suppression: A quantitative review. Clinical Psychology Review, 32(3), 189-201. doi:10.1016/j. cpr.2012.01.001

McCrady, B. S. (1998). Recent research in twelve-step program. In W. G. Graham, F. Fasam, \& T. K. Shultz (Eds.), Principles of addiction medicine (pp. 707-717). Chevy Chase, MD: American Society of Addiction Medicine.

Ouimette, P. C., Moos, R. H., \& Finney, J. W. (1998). Influence of outpatient treatment and 12-step group involvement on one-year substance abuse treatment outcomes. Journal of Studies on Alcohol, 59(5), 513-522. doi:10.15288/jsa. 1998.59.513

Owen, P. L., Slaymaker, V., Torigan, J. S., McCrady, B. S., Epstein, E. E., Kaskutas, L. A., Humphreys, K., \& Miller, W. R. (2003). Participation in Alcoholics Anonymous: Intended and unintended change mechanisms. Alcoholism, Clinical and Experimental Research, 27(3), 524-532. doi:10.1097/01.ALC. 0000057941.57330 .39

Pisani, V. D., Fawcett, J., Clark, D. C., \& McGuire, M. (1993). The relative contributions of medication adherence and AA meeting attendance to abstinent outcome for chronic alcoholics. Journal of Studies on Alcohol, 54(1), 115-119. doi:10.15288/ jsa.1993.54.115

Potenza, M. N., Gola, M., Voon, V., Kor, A., \& Kraus, S. W. (2017). Is excessive sexual behaviour an addictive disorder? The Lancet Psychiatry, 4(9), 663-664. doi:10.1016/S22150366(17)30316-4

Recker, G. T., \& Wong, P. T. (1988). Aging as an individual process: Toward a theory of personal meaning. In J. E. Bitten \& V. L. Bengston (Eds.), Emergent theories of aging (pp. 216-246). New York, NY: Springer.

Reid, R. C. (2010). Differentiating emotions in sample men in treatment for hypersexual behavior. Journal of Social Work Practice in the Addictions, 10(2), 197-213. doi:10.1080/ 15332561003769369

Reid, R. C. (2013). Personal perspectives on hypersexual disorder. Sexual Addiction \& Compulsivity, 20(1-2), 4-18. doi:10.1080/ 10720162.2013.772876

Reid, R. C., Garos, S., \& Carpenter, B. N. (2011). Reliability, validity, and psychometric development of the Hypersexual
Behavior Inventory in an outpatient sample of men. Sexual Addiction \& Compulsivity, 18(1), 30-51. doi:10.1080/ 10720162.2011.555709

Ronel, N. (1998). Narcotics Anonymous: Understanding the "Bridge of recovery." Journal of Offender Rehabilitation, 27(1-2), 179-197. doi:10.1300/J076v27n01_13

Ronel, N. (2012). Goes with the wind: Twelve-step program therapy. Ramat Gan, Israel: Bar-Ilan University (Hebrew).

Rubin, D. B. (2009). Multiple imputation for nonresponse in surveys (Vol. 307). New York: Wiley.

Schneider, J. P., \& Weiss, R. (2001). Cybersex exposed. Center City, MN: Hazelden.

Tangney, J. P., Baumeister, R. F., \& Boone, A. L. (2004). High self-control predicts good adjustment, less pathology, better grades, and interpersonal success. Journal of Personality, 72(2), 271-324. doi:10.1111/j.0022-3506.2004.00263.x

The Society for the Advancement of Sexual Health [SASH]. (2008). Sexual addiction. Retrieved September 21, 2008, from http://www.sash.net/

Walsh, D. C., Hingson, R. W., Merrigan, D. M., Levenson, S. M., Cupples, L. A., Heeren, T., Coffman, G. A., Becker, C. A., Barker, T. A., Hamilton, S. K., McGuire, T. G., \& Kelly, C. A. (1991). A randomized trial of treatment options for alcohol-abusing workers. The New England Journal of Medicine, 325(11), 775-782. doi:10.1056/NEJM199109123 251105

Ware, J. E., Snow, K. K., Kosinski, M., \& Gandek, B. (1993). SF-36 health survey: Manual and interpretation guide. Boston, MA: New England Medical Center, The Health Institute.

Wegner, D. M., Schneider, D. J., Carter, S., \& White, T. (1987). Paradoxical effects of thought suppression. Journal of Personality and Social Psychology, 53(1), 5-13. doi:10.1037/ 0022-3514.53.1.5

Wilson, W. (1939/2001). Alcoholics Anonymous, New York, NY: Alcoholics Anonymous World Services, Inc.

Wright, P. J. (2010). Sexual compulsivity and 12-step peer and sponsor supportive communication: A cross-lagged panel analysis. Sexual Addiction \& Compulsivity, 17(2), 154-169. doi:10.1080/10720161003796123

World Health Organization [WHO]. (1992). The ICD-10 classification of mental and behavioural disorders. Clinical descriptions and diagnostic guidelines. Geneva, Switzerland: World Health Organization.

World Health Organization [WHO]. (2017). ICD-11 beta draft. Retrieved from http://apps.who.int/classifications/icd11/browse/ 1-m/en. Accessed on: August 30, 2017.

Zimet, G. D., Dahlem, N. W., Zimet, S. G., \& Farley, G. K. (1988). The mulitdimensional scale of perceived social support. Journal of Personality Assessment, 52(1), 30-41. doi:10.1207/ s15327752jpa5201_2 